\title{
Predictors of Management Outcomes in Pathological Small Bowel Surgical Emergencies: A Prospective Study in a Busy Emergency Unit
}

\author{
AHMED M. HASSAN, M.D.; AHMED NABIL, M.D., M.R.C.S. (Eng); SAMUEL NEMR, M.Sc.; \\ HESHAM AMER, M.D. and AYMAN M.A. OSMAN, M.D., M.R.C.S. (Eng) \\ The Department of General Surgery, Faculty of Medicine, Cairo University, Egypt
}

\begin{abstract}
Background: The management of pathological small bowel disorders in the emergency department is challenging, and is linked to higher morbidity and mortality rates.

Aim of Study: The aim of this study was to identify the main factors that could help predict the management outcomes in pathological small bowel surgical emergencies (PSBSEs).

Patients and Methods: All patients presenting with PSBSEs to the Emergency Unit over a 6-months period were prospectively studied. Data about patient-related, assessment-related, pathology-related, and management-related variables; 90-day morbidity; as well as mortality were all recorded. Univariate and multivariate analyses were carried out to identify the predictors of management outcomes in PSBSEs.

Results: Our study included 107 patients. The most frequently encountered PSBSEs were obstruction and/or strangulation (64 cases, 59.8\%). Management was operative in 88 cases $(82.2 \%)$. Overall, 30 cases $(28 \%)$ developed morbidity, and 7 cases $(6.5 \%)$ died. In univariate analysis, 14 different factors were associated with a significantly increased risk of morbidity; whereas in multivariate analysis, only 5 factors were found to be significant predictors of 90-day morbidity. The highest odds of morbidity were associated with reoperation [Odds Ratio $(\mathrm{OR})=11.2,95 \% \mathrm{CI}=6.7-18.3, p=0.001$ ] and hemodynamic status [OR=9.7, 95\% CI=2.8-21.5, $p=0.001]$.

Conclusion: Constant abdominal pain at presentation, hemodynamic instability, midline surgical incision, operative time $>! 2$ hours, and re-operation were all associated with a significantly increased risk of 90-day morbidity in patients with PSBSEs.
\end{abstract}

Key Words: Predictors - Outcomes - Pathological small bowel emergencies.

\section{Introduction}

THE surgeon often faces a challenge when performing an emergency small bowel resection. The

Correspondence to: Dr. Ahmed M. Hassan, The Department of General Surgery, Faculty of Medicine, Cairo University, Egypt small intestine is a complicated organ that serves a variety of purposes. It can digest, absorb, and secrete, as well as perform endocrine functions. It also protects the internal environment from unpleasant ingested substances, luminal bacteria and their toxins [1]. Aside from various types of traumatic bowel injuries, there is a variety of pathological disorders that can affect the small bowel [2]. Among those, small bowel obstruction (SBO) is a common disorder. In patients with SBO; symptoms at presentation, physical findings and laboratory tests are not sensitive or specific enough to detect which patients have co-existing strangulation or ischemia; which presents a difficulty in clinical management [3]. To overcome diagnostic uncertainty in such cases, imaging is now widely used not only to diagnose SBO but also to detect complications that might necessitate immediate surgery [4].More recent studies have focused on the various computed tomographic (CT) signs in SBO to see if they can identify which patients need surgery and which patients can be managed conservatively

Small bowel disease management in the emergency department is thought to be an independent risk factor for postoperative morbidity and mortality [6]. Based on the underlying pathology, timing of presentation (early or late), and concomitant comorbidities; several studies of small intestinal emergency procedures have estimated the overall morbidity and mortality to be around $30 \%$ and $15 \%$ respectively. Different morbidities (e.g. metabolic, cardiovascular, infectious, respiratory) can significantly increase the risk of mortality [7]. Here, we conducted a prospective, non-randomized, analytical study over a 6-months period in order to identify the main factors that could help predict 
the management outcomes in pathological small bowel surgical emergencies (PSBSEs).

\section{Patients and Methods}

\section{Study design and population:}

All patients presenting with pathological small bowel surgical emergencies (PSBSEs) to the Emergency Unit (EU), Kasr Al-Aini Hospital, Cairo University, between September 2017 and February 2018 were prospectively studied. Pathological small bowel surgical emergencies were defined as "All acute non-traumatic surgical conditions affecting the jejunum and/or ileum, and requiring prompt management in an emergency surgical unit". Accordingly, a wide spectrum of surgical disorders fell under the entity "PSBSEs" (Table 1, Figs. 1-3). Informed consent was obtained from all patients. The study protocol was approved by

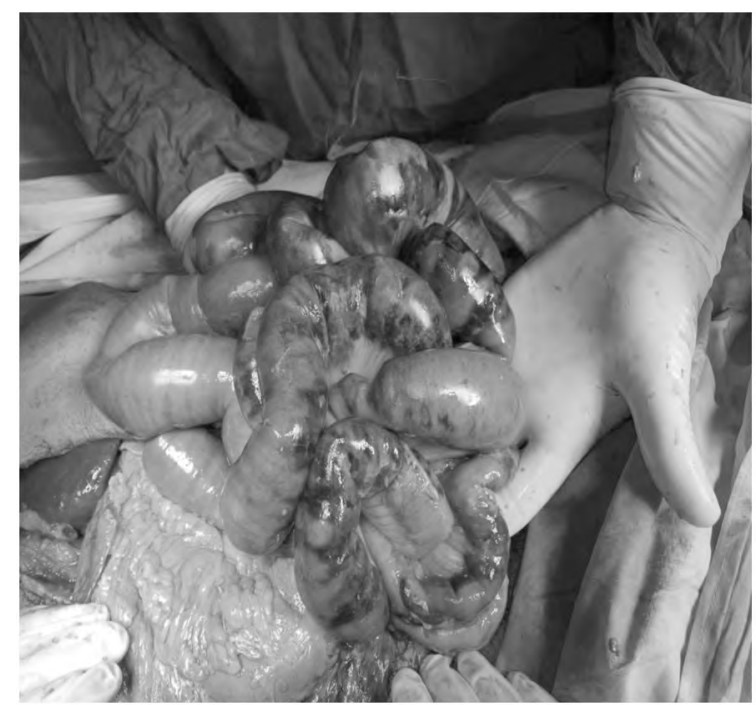

(A)

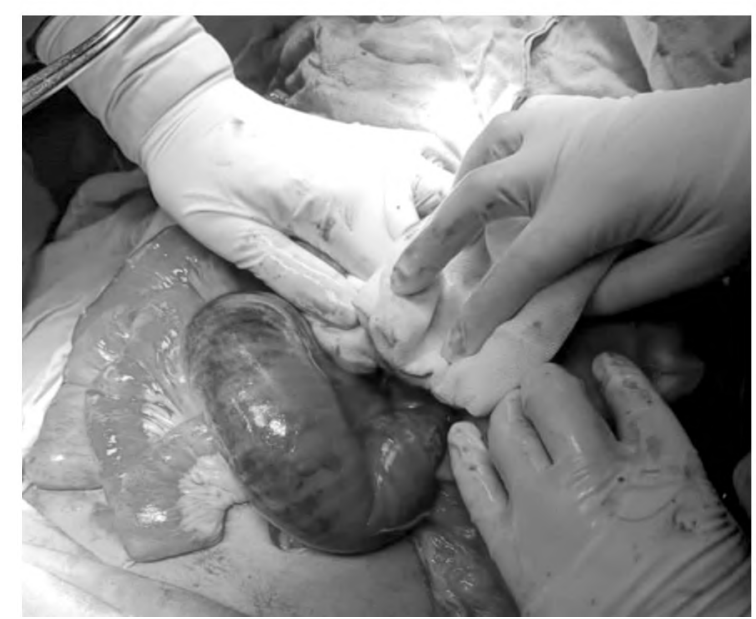

(C) the institutional ethical committee and conformed to the provisions of the Declaration of Helsinki (as revised in Seoul, Korea, October 2008).

Table (1): Different types of pathological small bowel surgical emergencies (PSBSEs).

\begin{tabular}{|c|c|}
\hline Types & Examples \\
\hline $\begin{array}{l}\text { 1- Obstruction \&/or } \\
\text { strangulation }\end{array}$ & $\begin{array}{l}\text { Adhesions, tumors, obstructed \&/or } \\
\text { strangulated external abdominal her- } \\
\text { nias, internal hernias, intussusception, } \\
\text { foreign body ingestion }\end{array}$ \\
\hline 2- Inflammatory & Crohn's disease, tuberculosis, typhoid \\
\hline 3- Vascular & $\begin{array}{l}\text { Acute mesenteric ischemia (occlusive } \\
\text { or non-occlusive) }\end{array}$ \\
\hline 4- Postoperative & Anastomotic dehiscence \\
\hline 5- Miscellaneous & $\begin{array}{l}\text { Incarcerated hernias, foreign body in- } \\
\text { gestion (non-obstructive) }\end{array}$ \\
\hline
\end{tabular}

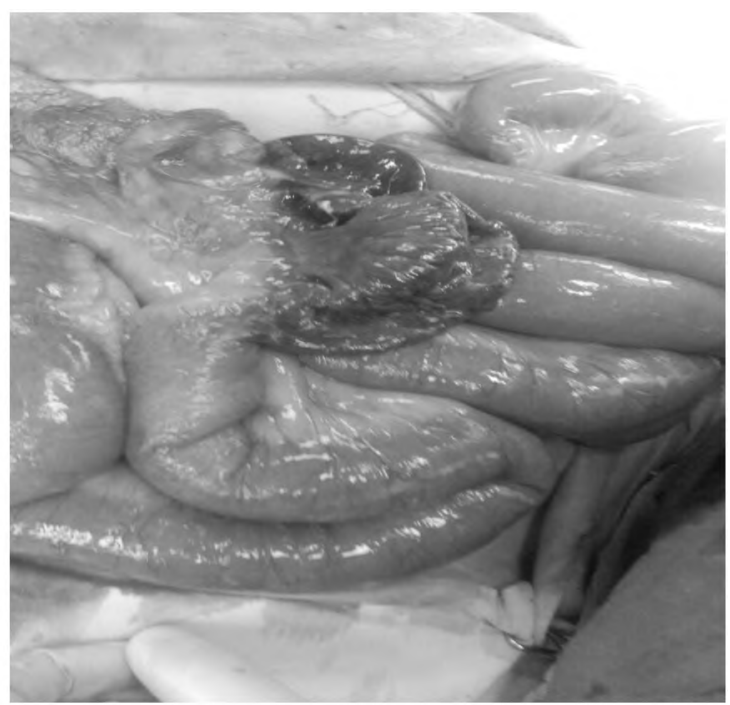

(B)

Fig. (1A,B,C): Three cases of acute mesenteric ischemia in our study. 


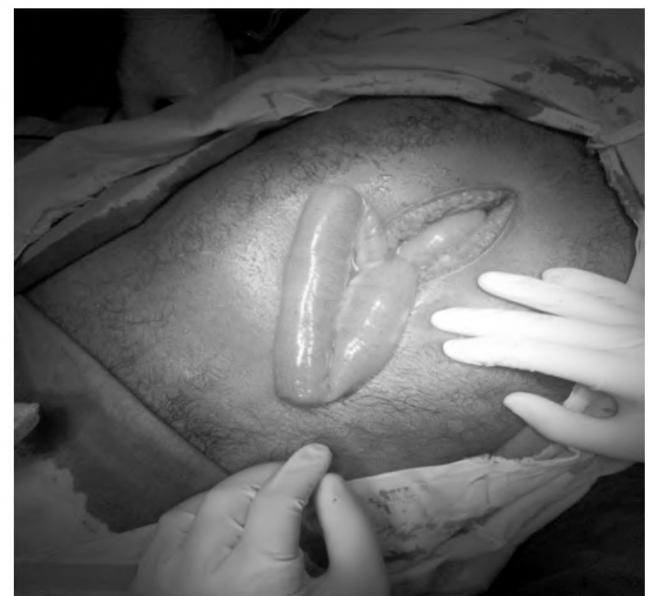

(A)
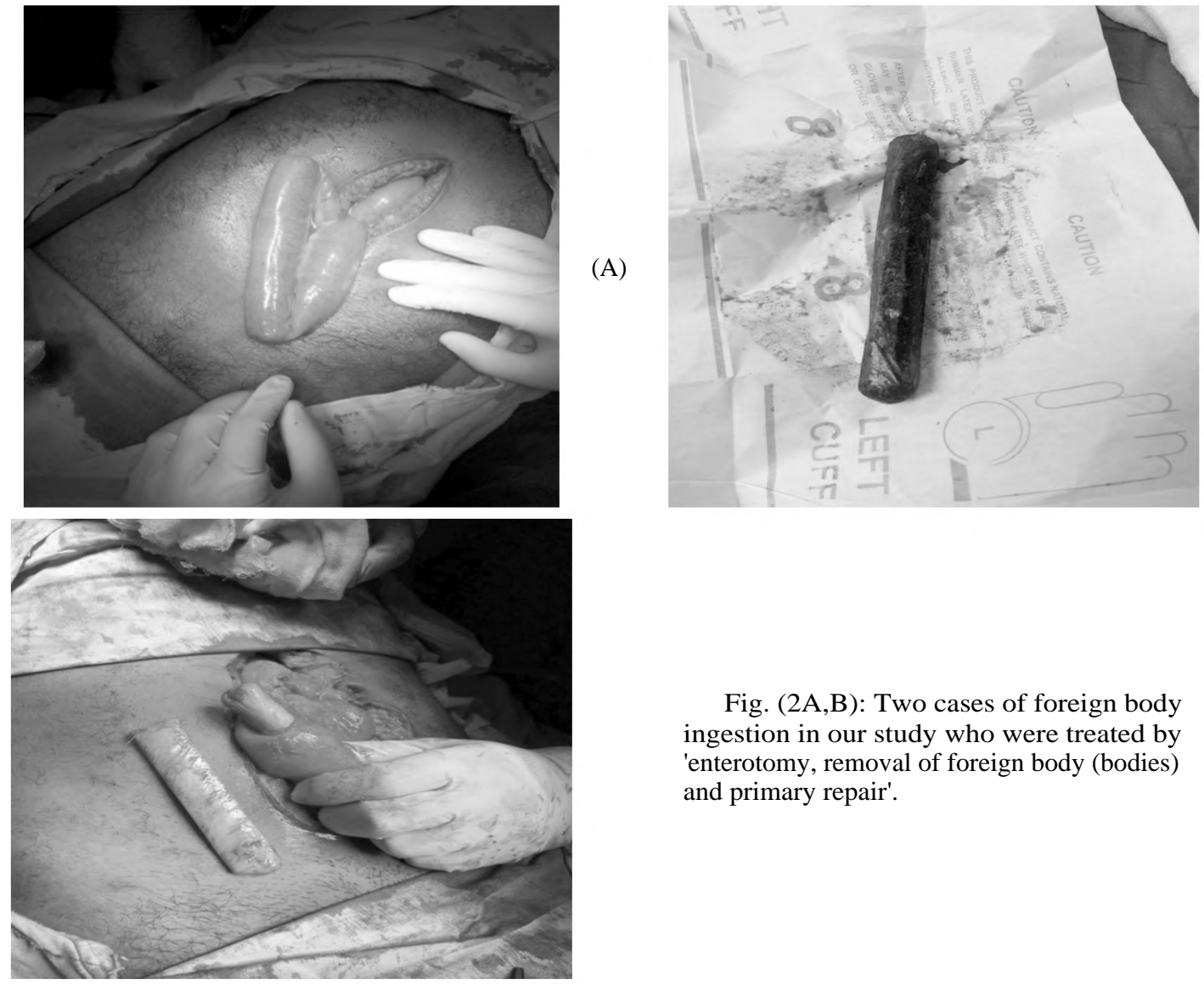

(B)
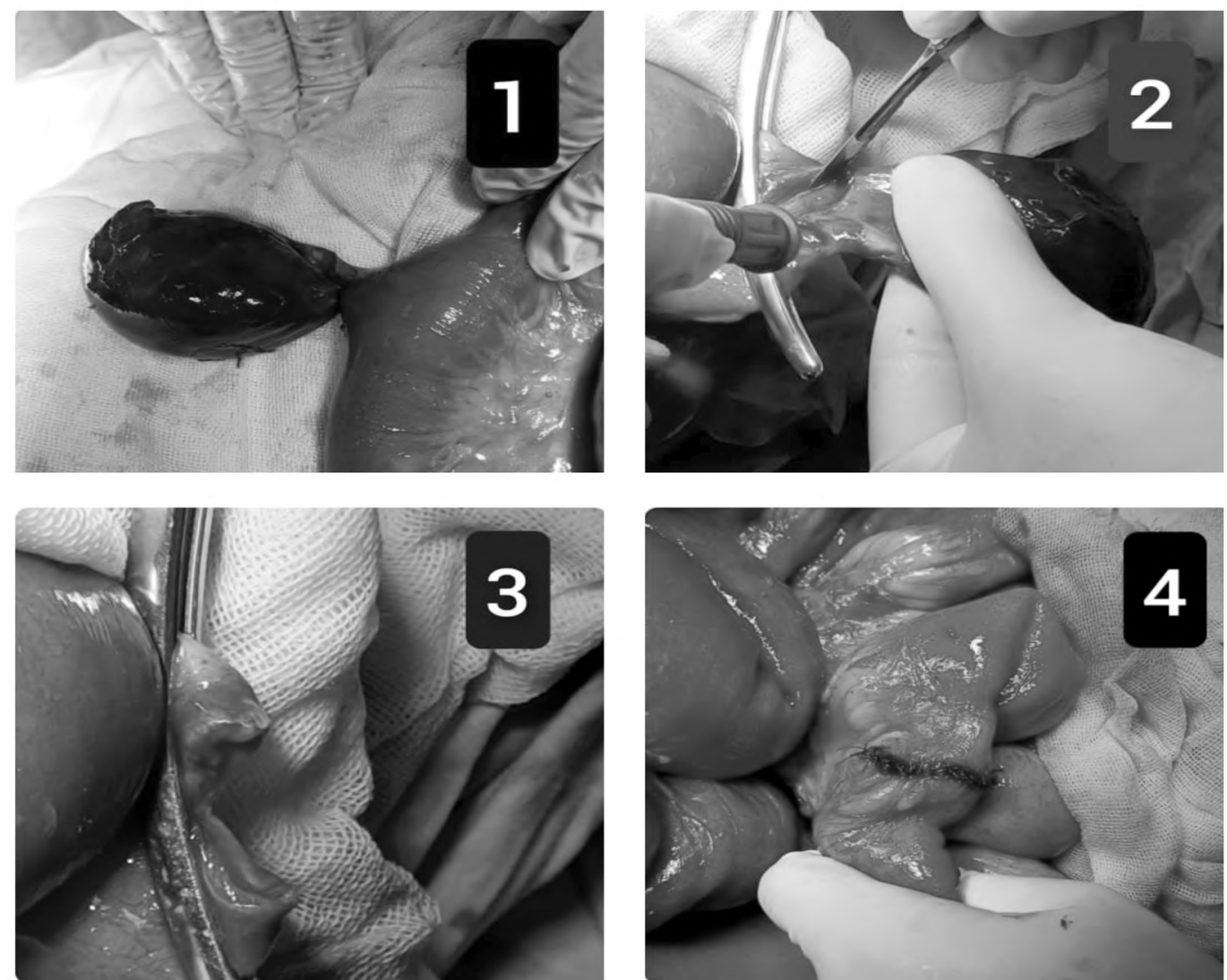

Fig. (3): Resection of a gangrenous twisted Meckel's diverticulum in one of the study patients. 
All patients who presented to the EU over the study period with "acute abdomen" were subjected to a strict preliminary work-up protocol, aiming to identify, assess and resuscitate -if needed- patients with PSBSEs. This preliminary workup included a baseline assessment of the vital signs (blood pressure, pulse, temperature, respiratory rate) and the level of consciousness, full historytaking (including special habits e.g. smoking, drug abuse; co-morbidities e.g. diabetes, ischemic heart disease; previous abdominal surgery), as well as thorough general and abdominal examination. Patients with a body mass index of $>30 \mathrm{~kg} / \mathrm{m}^{2}$ were labeled "obese". If the possibility of a PSBSE was considered, further investigations were carried out. Those included:

a- Laboratory investigations (complete blood count, random blood sugar, liver \& kidney functions tests, serum electrolytes, coagulation profile, arterial blood gases, cross-matching, serum amylase in patients with upper or generalized abdominal pain).

b- Radiological investigations [plain X-ray chest (erect), plain X-ray abdomen (erect \& supine), CT scan of the abdomen \& pelvis with intravenous (+/- oral) contrast for better assessment and delineation of bowel pathology].

At this stage, in all patients with either a clear diagnosis or any degree of suspicion of PSBSE, two wide-bore cannulas, a nasogastric tube, and a urinary catheter were inserted. Surrogates of organspecific perfusion: Urine output and capillary refill time were also recorded. The baseline recordings of vital signs, urine output, level of consciousness, and capillary refill time were used to assess the patient's hemodynamic status upon admission. If signs of shock were present, fluid resuscitation was initiated according to the Advanced Trauma Life Support (ATLS) guidelines [8]. Patients with septic shock were clinically identified by a serum lactate level of $>2 \mathrm{mmol} / \mathrm{L}$ and the requirement of a vasopressor to maintain a mean arterial pressure of $\geq 65 \mathrm{mmHg}$ in the absence of hypovolemia [9] The 2016 Surviving Sepsis Campaign International Guidelines for Management of Severe Sepsis and Septic Shock were followed for the management of patients with sepsis [10]. The Eastern Cooperative Oncology Group (ECOG) Performance Status was used to assess the functional status of all patients, whereas the American Society of Anesthesiologists (ASA) Physical Status Classification system was used to assess their fitness for surgery [11,12] .

Guided by the history, clinical examination, and investigations, a prompt decision regarding each patient's management strategy, whether conservative or surgical, was made by the EU surgical team. In selected cases, diagnostic laparoscopy was used to confirm the diagnosis. All patients in the 'conservative management' group were treated using a "Drip \& Suck" approach, with serial monitoring of hemodynamic parameters, blood tests \& bowel motions; serial abdominal examinations; and liberal use of diagnostic imaging. If no remarkable response was noted within 72 hours of conservative management or if any deterioration occurred, surgical management was promptly considered. In the 'surgical management' group, all patients underwent exploratory midline laparotomy under general anesthesia, except those with complicated hernias in whom the surgical incisions were dictated by the site of the hernia defect(s). The type of bowel pathology, if any, was identified. The exact site of the pathology, its distance from the duodenojejunal flexure (DJF) "in case of jejunal pathology" and from the ileocaecal junction (ICJ) "in case of ileal pathology" was also reported. Seven different types of surgical procedures were proposed for dealing with different types of PSBSEs. Those included resection \& primary anastomosis; resection \& stoma formation; diversion only; primary repair / enterotomy \& primary repair; hernia reduction \& repair; others (e.g. adhesiolysis, fecal dis-impaction, milking of foreign body; application of warm foments); and abdominal closure without any intervention.

The choice of the most appropriate surgical procedure for every specific patient was made at the operating room by the most senior staff member of the EU surgical team, after careful consideration of a variety of factors including the patient's general condition \& hemodynamic status; the site, extent $\&$ severity of bowel pathology; as well as the condition of the bowel wall e.g. edema, tissue friability. In cases with doubtful viability of strangulated small bowel, warm packs were used to wrap the affected bowel for a minimum duration of 10 minutes while the anesthetist was requested to give $100 \%$ oxygen. Bowel viability was then re-assessed and a decision regarding further management was promptly taken.

Only patients who were diagnosed, either during the preliminary work-up or at the time of surgery (laparoscopy and/or laparotomy), with a PSBSE, were enrolled in the study. Meanwhile, those who were diagnosed -at any point- as having gastroduodenal, appendicular, large bowel, or any other abdominal pathology with no small bowel involvement were excluded from the study. 
Patients who underwent surgery were closely monitored postoperatively in the surgical ward, or the Intensive Care Unit (ICU) if indicated. Intravenous fluids, antibiotics, and analgesics were prescribed, as necessary, according to the performed procedure and the patient's needs. Patients in the ICU were moved to the surgical ward once their condition was stabilized. Drains were removed once the daily output was serious and was less than $30 \mathrm{cc}$. All the study patients were discharged home once complete recovery was ensured and postoperative complications, if any, were appropriately dealt with (Fig. 4). Patients were instructed to come for follow-up at 2 weeks, 1 month \& 3 months from the time of initiation of successful conservative management or from the time of surgery. All postoperative complications in the first 90 days after surgery were reported. The ClavienDindo Classification of Surgical Complications (CDCSC) was used for grading of postoperative complications [13]. According to the CDCSC, complications were classified into five grades, with grade I being defined as "Any deviation from the normal postoperative course without the need for pharmacological treatment / interventions beyond the administration of antiemetics, antipyretics, analgesics, diuretics, electrolytes \& physiotherapy", whereas grade V being defined as "Death".
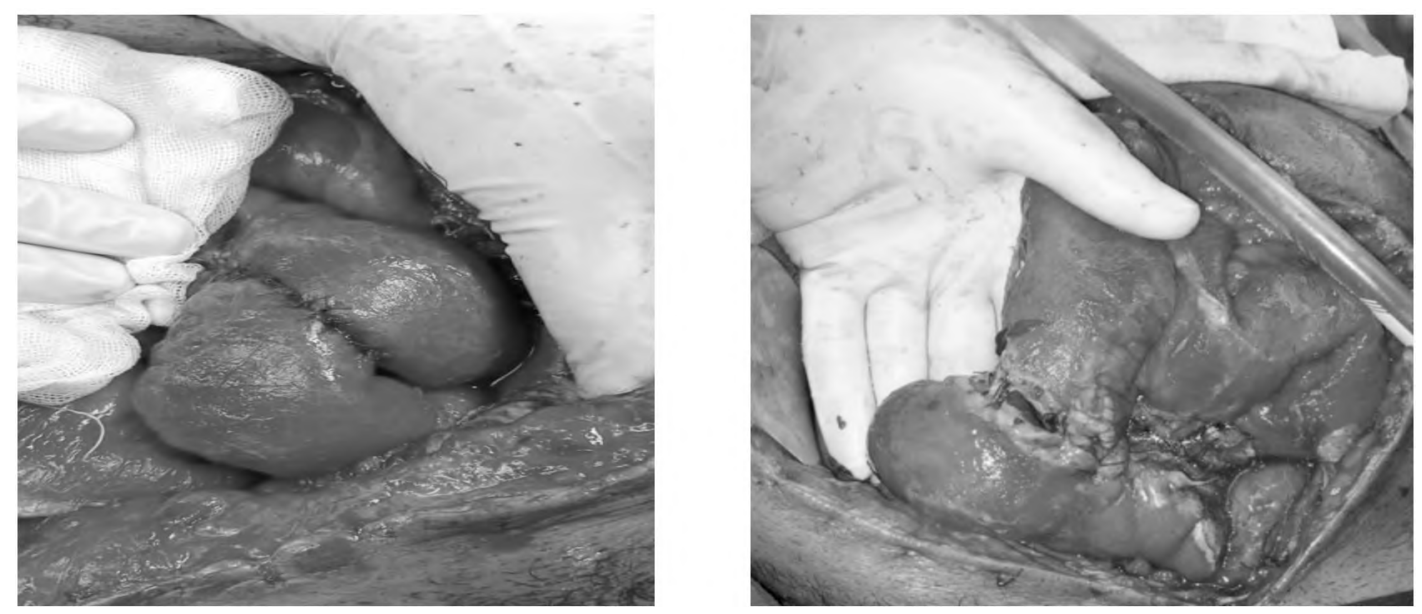

Fig. (4): Anastomotic dehiscence following resection \& primary anastomosis for a gangrenous ileal loop in a patient with mesenteric vascular occlusion.

\section{Data collection:}

Data about patient-related variables [age, gender, special habits, comorbidities, previous abdominal surgery]; assessment-related variables at presentation [duration of symptoms (from the onset of symptoms To presentation), pattern of abdominal pain, hemodynamic status, presence of fever and/or leucocytosis, ECOG Performance Status, ASA score]; pathology-related variables [type of PSBSE, part of small bowel involved, distance from DJF in case of jejunal pathology, distance from ICJ in case of ileal pathology, bowel viability, associated colonic involvement]; management-related variables [management strategy (conservative / operative), surgical incision used -if operative management was carried out-, type of surgical procedure(s) performed, need for re-operation or ICU admission]; 90-day morbidity (including postoperative complications \& their grading according to the CDCSC); as well as mortality were all recorded.

\section{Statistical analysis:}

Values in our study were expressed as means and standard deviations (mean $\pm \mathrm{SD}$ ) or as numbers (\%). Mean values of different variables in both groups were compared using the unpaired $t$-test, whereas categorical variables were compared using the Chi-square test. Correlation between variables was calculated using Pearson's correlation coefficient $(r)$. A $p$-value $<0.05$ was considered statistically significant. Univariate and multivariate analyses were carried out to identify the predictors of management outcomes in PSBSEs. When statistical significance testing and multivariate analyses of morbidity \& mortality were performed, minor postoperative complications that were classified as grade I according to the CDCSC were not counted as morbidity; whereas grades II, III \& IV complications formed the cornerstone of the morbidity analysis. Data were analyzed using Statistical Package for Social Sciences (SPSS) for Windows version 16 (IBM SPSS, Chicago, IL, USA). 


\section{Results}

Our study included 107 patients, $61(57 \%)$ were females and $46(43 \%)$ were males, with the most common age subgroup being 30-39 years (Fig. 5).

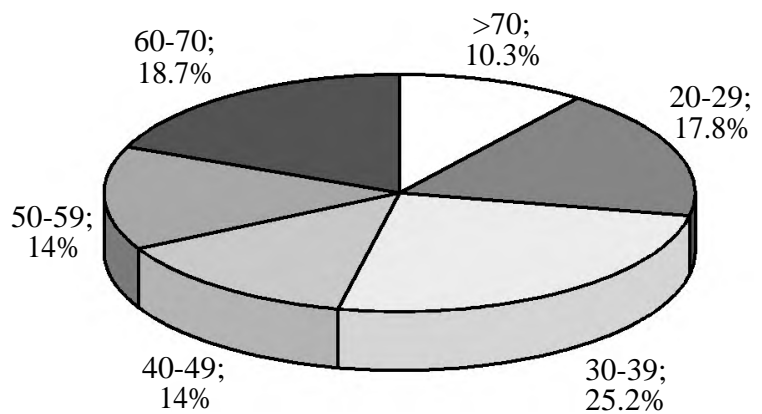

Fig. (5): Distribution of age subgroups in the study patients.

\section{Patients' characteristics and clinical features:}

In our series, 47 patients $(43.9 \%)$ had comorbidities, whereas 58 patients $(54.2 \%)$ had undergone previous abdominal surgery. Abdominal pain pattern at presentation was classified into two main categories: Intermittent pain [67 patients (62.6\%)] and constant pain [40 patients (37.4\%)]. Only 10 patients $(9.3 \%)$ were hemodynamically unstable at presentation, whereas 43 patients $(40.2 \%)$ had fever and/or leukocytosis. One hundred and one patients (94.4\%) had an ASA score of IIII. The most frequently encountered PSBSEs in our study were obstruction and/or strangulation (64 cases, 59.8\%). Among those, adhesive intestinal obstruction (I.O.) was the most common [33 cases $(30.8 \%)]$. Other types of PSBSEs (e.g. vascular, inflammatory, miscellaneous) were encountered in 43 cases $(40.2 \%)$. Management was operative in 88 cases $(82.2 \%)$. Of those, 75 cases underwent operative management from the start, and 56 cases $(63.6 \%)$ underwent laparotomy through a midline incision. The most commonly performed surgical procedure was resection and primary anastomosis (32 cases, $36.4 \%$ ). Thirty cases $(34.1 \%$ ) developed postoperative complications (morbidity), and 12 cases $(13.6 \%)$ were re-operated upon. The most commonly encountered postoperative complications in our series were wound complications [wound infection and/or wound dehiscence; 17 cases $(19.3 \%)]$. Of note, the 90 -day morbidity rate in the 'conservative management' group was $0 \%(0 / 19$ cases). Overall, in our study, 30 cases (28\%) developed morbidity, 16 cases $(15 \%)$ required ICU admission, and 7 cases $(6.5 \%)$ unfortunately passed away (Table 2).

Table (2): Clinical features of the study patients $(n=107)$.

\begin{tabular}{|c|c|c|c|c|c|}
\hline Variable & Number & Percent & Variable & Number & Percent \\
\hline Patient-related variables & & & Fecal impaction & 2 & 1.9 \\
\hline Age (years): & & & Retracted jejunostomy tube & 1 & 0.9 \\
\hline $20-29$ & 19 & 17.8 & Strangulation & 20 & 18.7 \\
\hline $30-39$ & 27 & 25.2 & External hernia & 18 & 16.8 \\
\hline $40-49$ & 15 & 14.0 & Internal hernia & 1 & 0.9 \\
\hline $50-59$ & 15 & 14.0 & Adhesive band & 1 & 0.9 \\
\hline $60-70$ & 20 & 18.7 & Vascular (Acute mesenteric ischemia) & 16 & 15.0 \\
\hline$>70$ & 11 & 10.3 & Inflammatory (Pathological perforation) & 5 & 4.7 \\
\hline & & & Miscellaneous & 22 & 20.6 \\
\hline Gender: & & & Incarcerated hernia & 15 & 14.0 \\
\hline Female & 61 & 57.0 & Foreign body ingestion & 5 & 4.7 \\
\hline Male & 46 & 43.0 & Meckel's diverticular pathology & 2 & 1.9 \\
\hline Special habits: & & & Part of small bowel involved: & & \\
\hline None & 62 & 57.9 & Jejunum & 24 & 22.4 \\
\hline Smoking & 41 & 38.3 & Ileum & 60 & 56.1 \\
\hline Smoking \& Tramadol addiction & 4 & 3.7 & Jejunum \& ileum & 4 & 3.7 \\
\hline Associated co-morbidity: & & & Unknown & 19 & 17.8 \\
\hline No & 60 & 56.1 & Bowel viability: & & \\
\hline Yes & 47 & 43.9 & Viable & 72 & 67.3 \\
\hline Hypertension & 3 & 2.8 & Non-viable & 35 & 32.7 \\
\hline Diabetes Mellitus & 6 & 5.6 & & & \\
\hline Heart disease (e.g IHD, AF) & 6 & 5.6 & Colonic involvement: & & \\
\hline Liver disease & 6 & 5.6 & Yes & 7 & 6.5 \\
\hline \multirow[t]{4}{*}{ Others } & 2 & 1.9 & No & 100 & 93.5 \\
\hline & & & Malignant pathology: & & \\
\hline & & & Yes & 4 & 3.7 \\
\hline & & & No & 103 & 96.3 \\
\hline
\end{tabular}


Table (2): Count.

\begin{tabular}{|c|c|c|c|c|c|}
\hline Variable & Number & Percent & Variable & Number & Percent \\
\hline Previous abdominal surgery: & 58 & 54.2 & Management-related variables & & \\
\hline Midline laparotomy & 9 & 8.4 & Management strategy: & & \\
\hline Trauma & 4 & 3.7 & Conservative & 32 & 29.9 \\
\hline Intestinal obstruction & 1 & 0.9 & Operative & 88 & 82.2 \\
\hline Feeding jejunostomy & 1 & 0.9 & From the start & 75 & 70.1 \\
\hline Ruptured ectopic pregnancy & 1 & 0.9 & After failure of conservative management & 13 & 12.1 \\
\hline Cystectomy \& ileal conduit & 3 & 2.8 & & & \\
\hline Appendicectomy & 11 & 10.3 & Time to surgical intervention & & \\
\hline Cholecystectomy (lap/open) & 7 & 6.5 & (Presentation To Operation): & & \\
\hline Hernia repair & 1 & 0.9 & $<6$ hours & $\begin{array}{l}27 / 88 \\
39 / 88\end{array}$ & 30.7 \\
\hline Caeserian section(s) & 14 & 13.1 & $\geq 6$ hours but $<24$ hrs & $\begin{array}{l}39 / 88 \\
27 / 88\end{array}$ & 44.3 \\
\hline Gynecological & 4 & 3.7 & $\geq 24$ hours & $22 / 88$ & 25.0 \\
\hline Nephrolithotomy & 1 & 0.9 & Surgical incision: & & \\
\hline Multiple surgical procedures & 11 & 10.3 & Midline incision & $56 / 88$ & 63.6 \\
\hline Assessment-related variables & & & Others & $32 / 88$ & 36.4 \\
\hline at presentation & & & Type of surgical procedure performed: & & \\
\hline Pattern of abdominal pain: & & & Resection \& primary anastomosis & $32 / 88$ & 36.4 \\
\hline Intermittent pain & 67 & 62.6 & Resection \& stoma formation & $9 / 88$ & 10.2 \\
\hline Constant pain & 40 & 37.4 & Diversion only & $0 / 88$ & 0.0 \\
\hline & & & Primary repair / enterotomy \& primary repair & $7 / 88$ & 8.0 \\
\hline $\begin{array}{l}\text { Duranon of sympioms } \\
\text { (Onset to Presentation). }\end{array}$ & & & Hernia reduction \& repair & $21 / 88$ & 23.9 \\
\hline $\begin{array}{l}\text { (Unset to Presentation): } \\
\leq 24 \text { hours }\end{array}$ & 33 & & Others (e.g. adhesiolysis, fecal disimpaction) & $16 / 88$ & 18.2 \\
\hline$>24$ hours & 74 & 69.2 & Abdominal closure without any intervention & $3 / 88$ & 3.4 \\
\hline Haemodynamic status: & & & Operative time: & & \\
\hline Stable & 97 & 90.7 & $<2$ hours & $42 / 88$ & 47.7 \\
\hline Unstable & 10 & 9.3 & $\geq 2$ hours & $46 / 88$ & 52.3 \\
\hline Fever \&/or leukocytosis: & & & Re-operation: & & \\
\hline Yes & 43 & 40.2 & Yes & $12 / 88$ & 13.6 \\
\hline No & 64 & 59.8 & No & $76 / 88$ & 86.4 \\
\hline ECOG Performance Status: & & & ICU admission: & & \\
\hline PS < 2 & 85 & 79.4 & Yes & 16 & 15.0 \\
\hline PS $\geq 2$ & 22 & 20.6 & No & 91 & 85.0 \\
\hline ASA score: & & & Morbidity: & & \\
\hline ASA I-III & 101 & 94.4 & No & 77 & 72.0 \\
\hline ASA IV-V & 6 & 5.6 & Yes & 30 & 28.0 \\
\hline & & & Mortality: & & \\
\hline $\begin{array}{l}\text { Pathology-related variables } \\
\text { Type of PSBSE: }\end{array}$ & & & No & 100 & 93.5 \\
\hline $\begin{array}{c}\text { Type of PSBSE: } \\
\text { Obstruction }\end{array}$ & 44 & 41.1 & Yes & 7 & 6.5 \\
\hline Adhesive intestinal obstruction & 33 & 30.8 & & & \\
\hline External hernia & 2 & 1.9 & & & \\
\hline Internal hernia & 2 & 1.9 & & & \\
\hline $\begin{array}{l}\text { Tumour (e.g. locally advanced } \\
\text { colorectal cancer, GIST) }\end{array}$ & 4 & 3.7 & & & \\
\hline
\end{tabular}

\section{Predictors of morbidity:}

Univariate analysis of predictors of morbidity revealed that 14 variables were statistically significant. These included co-morbidity, previous abdominal surgery, pain pattern at presentation, hemodynamic status, fever and/or leukocytosis, ASA score, part of small bowel involved, bowel viability, colonic involvement, type of definitive management, time to surgical intervention, surgical incision, re-operation, and ICU admission. Meanwhile, variables like age, gender, smoking history, duration of symptoms, ECOG Performance Status, presence of malignant pathology, and operative time were not statistically significant (Table 3 ). In the multivariate analysis, however, only 5 variables were significant predictors of 90-day morbidity. These included constant abdominal pain at presentation, hemodynamic instability, midline surgical incision, operative time $\geq 2$ hours, and re-operation (Table 4). Unfortunately, predictors of mortality could not be analyzed in this study due to the small sample size, where only 7 patients $(6.5 \%)$ died. 
Table (3): Univariate analysis of predictors of morbidity.

\begin{tabular}{|c|c|c|c|}
\hline Variable & No $(n=77)$ & Yes $(n=30)$ & $p$-value \\
\hline \multicolumn{4}{|l|}{ Age: } \\
\hline$<70$ years & $68(70.8 \%)$ & $28(29.2 \%)$ & \multirow[t]{2}{*}{0.724} \\
\hline$\geq 70$ years & $9(81.8 \%)$ & $2(18.2 \%)$ & \\
\hline \multicolumn{4}{|l|}{ Gender: } \\
\hline Male & $31(67.4 \%)$ & $15(32.6 \%)$ & \multirow[t]{2}{*}{0.361} \\
\hline Female & $31(75.4 \%)$ & $15(24.6 \%)$ & \\
\hline \multicolumn{4}{|l|}{ Smoking history: } \\
\hline No & $46(74.2 \%)$ & $16(25.8 \%)$ & \multirow[t]{2}{*}{0.546} \\
\hline Yes & $31(68.9 \%)$ & $14(31.1 \%)$ & \\
\hline \multicolumn{4}{|l|}{ Co-morbidity: } \\
\hline No & $49(81.7 \%)$ & $11(18.3 \%)$ & \multirow[t]{2}{*}{$0.012 *$} \\
\hline Yes & $28(59.6 \%)$ & $19(40.4 \%)$ & \\
\hline \multicolumn{4}{|l|}{ Previous abdominal } \\
\hline surgery: & & & \\
\hline No & $29(59.2 \%)$ & $20(40.8 \%)$ & \multirow[t]{2}{*}{$0.007 *$} \\
\hline Yes & $48(82.8 \%)$ & $10(17.2 \%)$ & \\
\hline \multicolumn{4}{|l|}{ Pain pattern } \\
\hline at presentation: & & & \\
\hline Intermittent pain & $61(91.0 \%)$ & $6(9.0 \%)$ & \multirow[t]{2}{*}{$0.001 *$} \\
\hline Constant pain & $1640.0 \%)$ & $24(60.0 \%)$ & \\
\hline \multicolumn{4}{|l|}{ Duration of symptoms: } \\
\hline$\leq 24$ hours & $24(72.7 \%)$ & $9(27.3 \%)$ & \multirow[t]{2}{*}{0.906} \\
\hline$>24$ hours & $53(71.6 \%)$ & $21(28.4 \%)$ & \\
\hline \multicolumn{4}{|l|}{ Haemodynamic status: } \\
\hline Stable & $76(88.4 \%)$ & $10(11.6 \%)$ & \multirow[t]{2}{*}{$0.001 *$} \\
\hline Unstable & $1(4.8 \%)$ & $20(95.2 \%)$ & \\
\hline \multicolumn{4}{|l|}{ Fever \&/or leukocytosis: } \\
\hline No & $57(89.1 \%)$ & $7(10.9 \%)$ & \multirow[t]{2}{*}{$0.001 *$} \\
\hline Yes & $20(46.5 \%)$ & $23(53.5 \%)$ & \\
\hline \multicolumn{4}{|l|}{ ECOG Performance } \\
\hline \multicolumn{4}{|l|}{ Status: } \\
\hline PS $<2$ & $64(75.3 \%)$ & $21(24.7 \%)$ & \multirow[t]{2}{*}{0.132} \\
\hline $\mathrm{PS} \geq 2$ & $13(59.1 \%)$ & $9(40.9 \%)$ & \\
\hline ASA score: & & & \\
\hline ASA I-III & $76(75.2 \%)$ & $25(24.8 \%)$ & $0.006^{*}$ \\
\hline ASA IV-V & $1(16.7 \%)$ & $5(83.3 \%)$ & \\
\hline $\begin{array}{l}\text { Part of small bowel } \\
\text { involved: }\end{array}$ & & & \\
\hline Jejunum & $15(62.5 \%)$ & $9(37.5 \%)$ & $0.013 *$ \\
\hline Ileum & $43(71.7 \%)$ & $17(28.3 \%)$ & \\
\hline Jejunum \& ileum & $0(0.0 \%)$ & $4(100.0 \%)$ & \\
\hline Bowel viability: & & & \\
\hline Viable & $62(80.5 \%)$ & $10(33.3 \%)$ & $0.001 *$ \\
\hline Non-viable & $15(19.5 \%)$ & $20(66.7 \%)$ & \\
\hline Colonic involvement: & & & \\
\hline No & $75(75.0 \%)$ & $25(25.0 \%)$ & $0.018 *$ \\
\hline Yes & $2(28.6 \%)$ & $5(71.4 \%)$ & \\
\hline Malignant pathology: & & & \\
\hline No & $74(71.8 \%)$ & $29(28.2 \%)$ & 0.890 \\
\hline Yes & $3(75.0 \%)$ & $1(25.0 \%)$ & \\
\hline Definitive management: & & & \\
\hline Conservative $(n=19)$ & $19(100.0 \%)$ & $0(0.0 \%)$ & $0.003 *$ \\
\hline Operative $(\mathrm{n}=88)$ & $58(65.9 \%)$ & $30(34.1 \%)$ & \\
\hline
\end{tabular}

Table (3): Count.

\begin{tabular}{llll}
\hline Variable & No $(\mathrm{n}=77)$ & Yes $(\mathrm{n}=30)$ & $p$-value \\
\hline $\begin{array}{l}\text { Time to surgical } \\
\text { intervention: }\end{array}$ & & & \\
$\quad<6$ hours & $13(48.1 \%)$ & $14(51.9 \%)$ & $0.019^{*}$ \\
$\quad \geq 6$ hours & $45(73.8 \%)$ & $16(26.2 \%)$ & \\
Surgical incision: & & & \\
$\quad$ Midline incision & $32(57.1 \%)$ & $24(42.9 \%)$ & $0.022^{*}$ \\
$\quad$ Others & $26(81,2 \%)$ & $6(18.8 \%)$ & \\
Operative time: & & & \\
$\quad<2$ hours & $31(75.6 \%)$ & $10(24.4 \%)$ & 0.073 \\
$\quad \geq 2$ hours & $27(57.4 \%)$ & $20(42.6 \%)$ & \\
Re-operation (n=88): & & & \\
$\quad$ No & $77(81.1 \%)$ & $18(18.9 \%)$ & $0.001^{*}$ \\
$\quad$ Yes & $0(0.0 \%)$ & $12(100.0 \%)$ & \\
ICU admission: & & & \\
$\quad$ No & $74(82.2 \%)$ & $16(17.8 \%)$ & $0.001^{*}$ \\
$\quad$ Yes & $3(17.6 \%)$ & $14(82.4 \%)$ & \\
\hline
\end{tabular}

Data are expressed as number $(\%) . \quad * p<0.05=$ Significant.

Table (4): Multivariate analysis of predictors of morbidity.

\begin{tabular}{llc}
\hline Variable & OR (95\% CI) & $p$-value \\
\hline Pain pattern at presentation (constant) & $2.6(1.7-4.8)$ & 0.015 \\
Haemodynamic status (unstable) & $9.7(2.8-21.5)$ & 0.001 \\
Surgical incision (midline) & $5.1(1.9-13.6)$ & 0.008 \\
Operative time ( $\geq 2$ hours) & $6.7(2.3-17.5)$ & 0.008 \\
Re-operation (yes) & $11.2(6.7-18.3)$ & 0.001 \\
\hline
\end{tabular}

Results are shown only for the variables that were significant at end of the analysis; other variables included in the multivariable analysis were co-morbidity (yes), ASA $>3$, fever \&/or leucocytosis (yes), bowel viability (non-viable), colonic involvement (yes), definitive management (operative), time to surgical intervention ( $<6 \mathrm{hrs}$ ), and ICU admission (yes). $(\mathrm{OR}=$ Odds ratio; $\mathrm{CI}=$ Confidence interval $)$.

\section{Discussion}

A wide range of pathologies, as well as various types of traumatic injuries, can affect the small bowel. The aim of this study was to identify the main factors that could help predict the management outcomes in pathological small bowel surgical emergencies (PSBSEs).

Our study observed 107 consecutive patients who presented to the Emergency Unit (EU), Kasr Al-Aini Hospital, Cairo University over a 6-months period with PSBSEs affecting the jejunum and/or ileum. Patients with gastroduodenal, appendicular, or large bowel pathologies with no small bowel involvement were excluded from the study. Overall, the 90-day morbidity rate in our series was $28 \%$ (30 cases), whereas the mortality rate was $6.5 \%$ ( 7 cases). These figures were higher than those published by Mohammed et al., [14] in their recent 
series of emergency small bowel resections [morbidity: $25 \%$ (15 cases); mortality: 3\% (2 cases)].

Small bowel surgical emergencies can include obstructive lesions (e.g. herniae, adhesions), vascular lesions (e.g. acute mesenteric ischemia), as well as cases with wall disruption, with some interactions in between [14]. In our study, 58 patients had a history of previous abdominal surgery (e.g. Caesarian section, appendectomy, cholecystectomy, midline laparotomy, others). Of those, 33 patients presented with adhesive I.O. Of note, adhesive I.O. was the most commonly encountered PSBSE in our series (30.8\%) and was most frequently observed in patients who had previously undergone appendectomy or midline laparotomy. According to Catena et al., [15], postoperative adhesions, which occur following about $67 \%-93 \%$ of abdominal procedures, present a major clinical concern that can result in intestinal obstruction, infertility, and pain. Band adhesions commonly develop following appendectomies, colorectal resections and gynecological operations [16].

In this study, univariate analysis revealed that 14 different factors were associated with a significantly increased risk of morbidity in patients with PSBSEs. These factors included the presence of co-morbidity, the absence of a history of previous abdominal surgery, constant abdominal pain at presentation, hemodynamic instability, fever and/or leukocytosis, ASA score IV-V, ileal involvement, non-viable bowel, colonic involvement, operative management, time to surgical intervention $<6$ hours, midline surgical incision, re-operation, and ICU admission. In the multivariate analysis, however, only 5 factors were found to be significant predictors of 90-day morbidity in patients with PSBSEs. These included constant abdominal pain at presentation, hemodynamic instability, midline surgical incision, operative time > 2 hours, and re-operation. The highest odds of morbidity were associated with re-operation [Odds Ratio $(\mathrm{OR})=11.2,95 \%$ $\mathrm{CI}=6.7-18.3, p=0.001]$ and hemodynamic status $[\mathrm{OR}=9.7,95 \% \mathrm{CI}=2.8-21.5, p=0.001]$. The aforementioned findings partially agreed with the recent study by Mohammed et al., [15] which revealed that, in univariate analysis, resection procedures and hemodynamic instability were associated with the highest risk of morbidity; whereas in multivariate analysis, age and presence of co-morbidities were the most significant variables. In a study by Margenthaler et al., [21], it was shown that poor preoperative performance status was a major risk factor for both morbidity and mortality, and that dependent functional health status was an independent risk factor for postoperative morbidity in
SBO patients. Another retrospective series of 323 patients that was conducted by Jeppesen et al., [20] found that daily use of systemic corticosteroids before surgery was related to an increased risk of morbidity, but not mortality. Furthermore, a study by Mitra [17] reported that male gender was associated with a higher risk of complications and anastomotic leak following intestinal resection and anastomosis. In our series, there were 4 cases of anastomotic leak, 2 of whom were males.

Unfortunately, because of the small sample size, we were unable to analyze the predictors of mortality. In a prospective series of 286 patients who were operated upon for postoperative adhesive SBO, Duron et al., [18] showed that early postoperative mortality was strongly linked to age and ASA class, whereas long-term mortality was strongly linked to postoperative complications. Another study by Teixeira et al., [19] suggested that early operative intervention for patients with acute SBO was associated with a considerable survival benefit, decreased incidence of local and systemic complications, as well as shorter hospitalization.

\section{Conclusion:}

Constant abdominal pain at presentation, hemodynamic instability, midline surgical incision, operative time > 2 hours, and re-operation were all associated with a significantly increased risk of 90-day morbidity in patients with pathological small bowel surgical emergencies. Further studies with larger sample sizes are, however, still needed to help analyze the predictors of mortality in this group of patients.

\section{References}

1- VALLICELLI C., COCCOLINI F., CATENA F., et al.: Small bowel emergency surgery: Literature's review. World Journal of Emergency Surgery, 6 (1): 1-5, 2011.

2- FARIA G., ALMEIDA A., MOREIRA H., et al.: Prognostic factors for traumatic bowel injuries: Killing time. World Journal of Surgery, 36 (4): 807-12, 2012.

3- PAULSON E.K. and THOMPSON W.M.: Review of Small-Bowel Obstruction: The Diagnosis and When to Worry. Radiology, 275 (2): 332-342, 2015.

4- BEMELMAN W.A., WARUSAVITARNE J., SAMPIETRO G.M., SERCLOVA Z., ZMORA O., LUGLIO G. and D'HOORE A.: ECCO-ESCP Consensus on Surgery for Crohn's Disease. Journal of Crohn's and Colitis, 2017.

5- SANTILLAN C.S.: Computed tomography of small bowel obstruction. Radiol. Clin. North Am., Jan. 51 (1): 17-27, 2013.

6- WYERS M.: Acute mesenteric ischemia: Diagnostic approach and surgical treatment. In Seminars in vascular surgery. WB Saunders, Pp. 9-20, 2010. 
7- TILSED J., CASAMASSIMA A., KURIHARA H., et al.: ESTES guidelines: Acute mesenteric ischaemia. European Journal of Trauma and Emergency Surgery, 42 (2): 25370, 2016.

8- Advanced trauma life support (ATLS® 2013): The ninth edition. J. Trauma Acute Care Surg., May 74 (5): 13636, 2013.

9- SINGER M., DEUTSCHMAN C.S., SEYMOUR C.W. et al.: The Third International Consensus Definitions for Sepsis and Septic Shock (Sepsis-3). JAMA, 315 (8): 801$810,2016$.

10- RHODES A., EVANS L.E., ALHAZZANI W., LEVY M.M., ANTONELLI M., FERRER R., KUMAR A., et al.: Surviving Sepsis Campaign: International Guidelines for Management of Sepsis and Septic Shock: 2016. Intensive Care Med., Mar. 43 (3): 304-377, 2017.

11- OKEN M., CREECH R., TORMEY D., et al.: Toxicity and response criteria of the Eastern Cooperative Oncology Group. Am. J. Clin. Oncol., 5: 649-655, 1982.

12-ASA House of Delegates: ASA physical status classification system. 2014. https://www.asahq.org/resources/clinicalinformation/asa-physical-status-classifi cation-system (accessed 3/10/2018), 2014.

13- CLAVIEN P.A., BARKUN J., de OLIVEIRA M.L., VAUTHEY J.N., DINDO D., SCHULICK R.D., et al.: The Clavien-Dindo classification of surgical complications: five-year experience. Ann. Surg., 250 (2): 187-96, 2009.

14- MOHAMMED H., AHMED M., KABBASH M. and SALEEM A.: Study of the Outcome of Emergency Small Bowel Resections Regarding Morbidity and Mortality. The Egyptian Journal of Hospital Medicine, 83 (1): 14561461, 2021.

15- CATENA F., Di SAVERIO S., COCCOLINI F., ANSA-
LONI L., De SIMONE B., SARTELLI M., et al.: Adhesive small bowel adhesions obstruction: Evolutions in diagnosis, management, and prevention. World Journal of Gastrointestinal Surgery, 8 (3): 222, 2016.

16- KASELAS C., MOLINARO F., LACREUSE I. and BECMEUR F.: Postoperative bowel obstruction after laparoscopic and open appendectomy in children: A 15-year experience. Journal of Pediatric Surgery, 44 (8): 1581$1585,2009$.

17- MITRA Dr.: Study of Emergency Intestinal Resection and Anastomosis in Adults. Journal of Medical Science and Clinical Research, 04. 13490-13500, 2016.

18- DURON J.J., du MONTCEL S.T., BERGER A., MUSCARI F., HENNET H., VEYRIERES M. and HAY J.M.: French Federation for Surgical Research: Prevalence and risk factors of mortality and morbidity after operation for adhesive postoperative small bowel obstruction. Am. J. Surg., Jun. 195 (6): 726-34, 2008.

19-TEIXEIRA P.G., KARAMANOS E., TALVING P., INABA K., LAM L. and DEMETRIADES D.: Early operation is associated with a survival benefit for patients with adhesive bowel obstruction. Ann. Surg., Sep. 258 (3): 459-65, 2013.

20- JEPPESEN, MAJA HAUNSTRUP, et al.: "Risk factors affecting morbidity and mortality following emergency laparotomy for small bowel obstruction: A retrospective cohort study". International Journal of Surgery, 28: 63$68,2016$.

21- MARGENTHALER J.A., LONGO W.E., VIRGO K.S., JOHNSON F.E., GROSSMANN E.M., SCHIFFTNER T.L., HENDERSON W.G. and KHURI S.F.: Risk factors for adverse outcomes following surgery for small bowel obstruction. Ann. Surg., Apr. 243 (4): 456-64, 2006. 


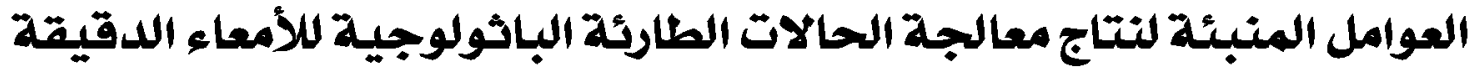

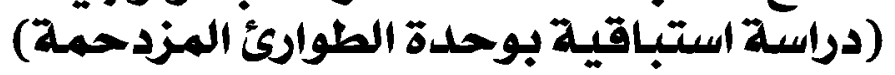

تهدف الدراسة إلى التعرف على العوامل الرئيسية التى تساعد فى التنبؤ بنتاج معالجة الحالات الباثولوجية الطارئة للآ معاء الدقيقة على الثى

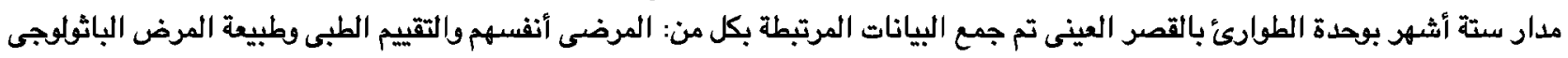
وطريقة العلاج المتبعة.

ومن ثم تم تسجيل معدل حدوث المرض ومعدل الوفاه على مدار تسعين يوماً منذ احالة المريض المستشفى قتم إجراء تحليل أحادى المتغير

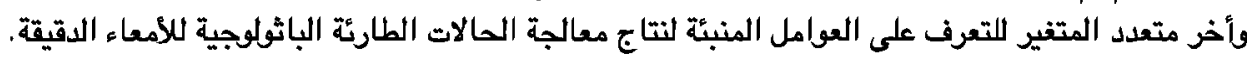

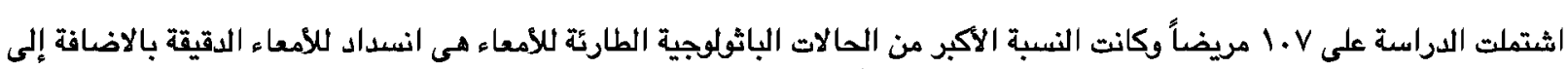

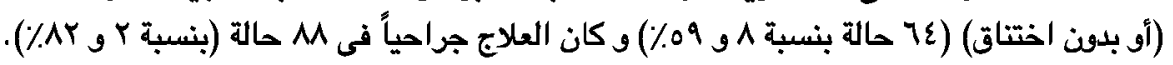

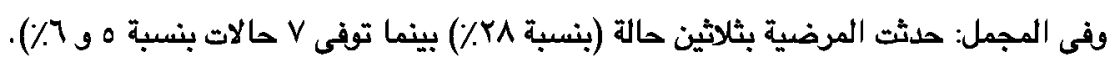
هوجد أن هناك عا عامل مختلف مرتبط بزيادة نسبة حدوث المرضية بصورة ملحوظة خلال التحليل أحادى المتفير في حين أن التحليل

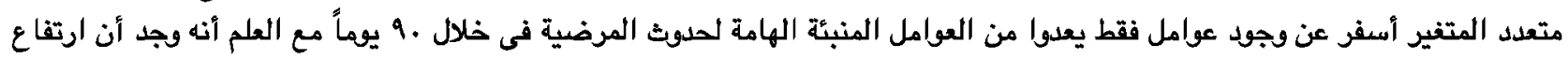

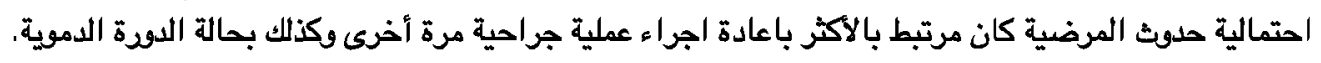
الاستنتاج العوامل المرتبطة بزيادة نسبة حدوث المرضية بصورة ملحوظة في خلال ـو يوماً في مرضى الحالات الطارئة الباثولوجية للاكعاء الدقيقة كانت كالآتى: ألم البطن المستمر عند الاحالة إلى المستشفى وعدم استقرار الورة الدموية والجرحح الوبسطية الاستكشافية للبطن وزيادة الزمن المستفق

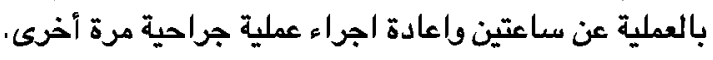

